\title{
What drives the observed variability of $\mathrm{HCN}$ in the troposphere and lower stratosphere?
}

\author{
Q. Li ${ }^{1}$, P. I. Palmer ${ }^{1}$, H. C. Pumphrey ${ }^{1}$, P. Bernath ${ }^{2}$, and E. Mahieu ${ }^{3}$ \\ ${ }^{1}$ School of GeoSciences, The University of Edinburgh, Edinburgh, UK \\ ${ }^{2}$ Department of Chemistry, University of York, York, UK \\ ${ }^{3}$ Institute of Astrophysics and Geophysics, University of Liège, Liège, Belgium
}

Received: 7 April 2009 - Published in Atmos. Chem. Phys. Discuss.: 4 May 2009

Revised: 26 September 2009 - Accepted: 28 September 2009 - Published: 10 November 2009

\begin{abstract}
We use the GEOS-Chem global 3-D chemistry transport model to investigate the relative importance of chemical and physical processes that determine observed variability of hydrogen cyanide $(\mathrm{HCN})$ in the troposphere and lower stratosphere. Consequently, we reconcile groundbased FTIR column measurements of HCN, which show annual and semi-annual variations, with recent space-borne measurements of $\mathrm{HCN}$ mixing ratio in the tropical lower stratosphere, which show a large two-year variation. We find that the observed column variability over the ground-based stations is determined by a superposition of $\mathrm{HCN}$ from several regional burning sources, with GEOS-Chem reproducing these column data with a positive bias of $5 \%$. GEOSChem reproduces the observed $\mathrm{HCN}$ mixing ratio from the Microwave Limb Sounder and the Atmospheric Chemistry Experiment satellite instruments with a mean negative bias of $20 \%$, and the observed $\mathrm{HCN}$ variability with a mean negative bias of $7 \%$. We show that tropical biomass burning emissions explain most of the observed $\mathrm{HCN}$ variations in the upper troposphere and lower stratosphere (UTLS), with the remainder due to atmospheric transport and HCN chemistry. In the mid and upper stratosphere, atmospheric dynamics progressively exerts more influence on $\mathrm{HCN}$ variations. The extent of temporal overlap between African and other continental burning seasons is key in establishing the apparent bienniel cycle in the UTLS. Similar analysis of other, shorter-lived trace gases have not observed the transition between annual and bienniel cycles in the UTLS probably because the signal of inter-annual variations from surface emission has been diluted before arriving at the lower stratosphere (LS), due to shorter atmospheric lifetimes.
\end{abstract}

Correspondence to: $\mathrm{Q}$. $\mathrm{Li}$

(q.li@ed.ac.uk)

\section{Introduction}

Hydrogen cyanide $(\mathrm{HCN})$ is a tracer of biomass burning (BB; Lobert et al., 1990; Holzinger et al., 1999) and could play a non-negligible role in the nitrogen cycle ( $\mathrm{Li}$ et al., 2000, 2003). Before we can confidently use HCN to infer its surface sources and sinks we must first develop a robust understanding of the chemical and physical processes that determine observed variability.

Laboratory and field measurements support that BB is the major source for atmospheric HCN but the magnitude is still uncertain (0.1-3.2 Tg N/year) (Li et al., 2003 and references therein). Automobile exhaust and industrial processes represent additional minor tropospheric sources of HCN (Lobert et al., 1991; Bange and Williams, 2000; Holzinger et al., 2001). The HCN source from burning domestic biofuel is still unclear with studies reporting values from zero, based on laboratory fire measurements in Africa (Bertschi et al., 2003), to $0.2 \mathrm{TgN} /$ year based on analysis of aircraft concentration measurements over the western Pacific downwind of eastern Asia ( $\mathrm{Li}$ et al., 2003), the range probably reflecting regional differences in the nitrogen content of domestic biofuels. Ocean uptake has been hypothesized as the dominant tropospheric sink with values ranging from 0.73 to $1.0 \mathrm{Tg}$ N/year, where it is biologically consumed (Singh et al., 2003), leading to a lifetime of 5 months in the troposphere (Hamm and Warneck, 1990; Li et al., 2003). Additional minor sinks of $\mathrm{HCN}$ include atmospheric oxidation by the hydroxyl radical $(\mathrm{OH})$ and $\mathrm{O}\left({ }^{1} \mathrm{D}\right)$, photolysis, yielding a stratospheric lifetime of a few years (Cicerone and Zellner, 1983; Brasseur et al., 1985). Li et al. (2000, 2003) showed using the GEOS-Chem global 3-D model that the observed seasonal variation of the $\mathrm{HCN}$ tropospheric column in different regions of the world was consistent with a scenario where $\mathrm{BB}$ provides the main source and ocean uptake provides the

Published by Copernicus Publications on behalf of the European Geosciences Union. 
main sink. Recently Lupu et al. (2009) reproduced similar seasonal variations of the HCN tropospheric column using the GEM-AQ tropospheric global 3-D model.

Ground-based HCN column measurements from Fourier transform infrared (FTIR) spectrometers, available at several sites around the world (Mahieu et al., 1995, 1997; Rinsland et al., 1999, 2000, 2001, 2007; Zhao et al., 2000, 2002), represent important but sparse constraints to our quantitative understanding of HCN spatial and temporal distributions. As we show later these data show large variations on intraseasonal to yearly timescales. Recent analysis of satellite HCN measurements from the NASA Aura Microwave Limb Sounder (MLS) (Waters, 2006) and the Atmospheric Chemistry Experiment Fourier Transform Spectrometer (ACEFTS) (Boone et al., 2005) show an approximate 2-year cycle of HCN anomalies in the tropical upper troposphere and lower stratosphere (UTLS) (Pumphrey et al., 2008), hypothesized to be due to year-to-year variations in surface burning over Indonesia and Australia. This is supported by a recent model study of year-to-year variations of UTLS CO, another tracer of $\mathrm{BB}$, which showed that variations during 1994-1998 were primarily caused by year-to-year changes in surface burning (Duncan et al., 2007). The satellite measurements of HCN from MLS and ACE-FTS therefore potentially provide additional global constraints on BB emissions but first we have to reconcile the observed annual cycle from ground-based and 2-year cycle from MLS and ACEFTS measurements. We use the GEOS-Chem global 3-D chemical transport model (CTM) (Bey et al., 2001; Li et al., 2003) to understand the role of surface emissions, and atmospheric chemistry and transport in determining the observed variations of $\mathrm{HCN}$ from ground-based and space-borne measurements.

In the next section we describe the GEOS-Chem HCN simulation and evaluate model concentrations using groundbased FTIR and space-borne measurements. In Sect. 3 we examine the model ability to reproduce observed tropical HCN anomalies and in Sect. 4 we determine the importance of surface biomass burning emissions, atmospheric chemistry and transport in reproducing this tropical signal. We conclude the paper in Sect. 5.

\section{Description and evaluation of GEOS-Chem HCN simulation}

\subsection{Model description}

We use the GEOS-Chem global 3-D CTM (version 7.4.11) to simulate the atmospheric distribution of $\mathrm{HCN}$ from 2001 to 2008. Our calculations use assimilated meteorological analyses from the Goddard Earth Observing System v4 (GEOS-4, available from 1990 to 2006, used here from 2001 to 2003) and v5 (GEOS-5, available from 2003 to present, used here from 2004 to 2008) of the NASA GMAO (Global Model- ing and Assimilation Office), at 6-h temporal resolution (3-h for surface variables and mixed layer depths). We use the model with a horizontal resolution of $2^{\circ} \times 2.5^{\circ}$ (Lat. $\times$ Lon.) and with 30 levels in 2001-2003 (derived from the native 55 levels of GEOS-4) ranging from the surface to the mesosphere, 20 of which are below $12 \mathrm{~km}$. In 2004-2008, we run the model with the horizontal resolution of $2^{\circ} \times 2.5^{\circ}$ and with 47 levels (derived from the native 72 levels of GEOS-5) with same levels in the stratosphere and 17 more levels in the troposphere, using a re-gridded restart file from the earlier experiment of 2001-2003. The model outputs are interpolated onto the same levels. Here we focus on model details pertinent to the HCN simulation; for a more detailed description of the GEOS-Chem model we refer the reader to Bey et al. (2001) and Fiore et al. (2003).

The HCN simulations are conducted for a 8-year period (January 2001-December 2008), using the previous 24 months to remove initial conditions. Correspondingly, we study the ground-based observation from January 2001 to December 2008, and space-borne observations of ACEFTS (available from January 2004 to August 2007) and Aura MLS (available from September 2004 to December 2008). The time domain of our analysis is limited by the availability of BB emissions data (see below). We use fixed 3-D monthly mean $\mathrm{OH}$ fields, (described below), that linearize the HCN simulation, allowing us to describe total HCN concentrations as a linear sum of contributions from individual source regions/types. We assume no inter-annual variability of $\mathrm{OH}$ concentrations. For our experiments, we include two continental sources: BB and domestic biofuel burning. Figure 1 shows the ten source regions we study in this paper: North America (NA), South America (SA), Europe (EU), northern Africa (NAF), Southern Africa (SAF), Boreal Asia (BA), Southeast Asia (SE AS), and Indonesia and Australia (IND + AUS); Table 1 defines the latitude and longitude domain of each geographical region.

We use monthly mean $\mathrm{BB}$ emission estimate of $\mathrm{HCN}$, based on $\mathrm{CO}$ estimates from the Global Fire Emission Database version 2 (GFEDv2, available from 1997 to 2008; van der Werf et al., 2006), using an observed HCN:CO emission ratio of $0.27 \%$ over the western Pacific (Li et al., 2003). Figure 2 shows that global HCN BB emissions peak in August and to a lesser extent in January, with global annual mean values ranging from 0.56 to $0.77 \mathrm{Tg} \mathrm{N} /$ year over 2001-2008. The largest emissions originate from Africa, SA, IND + AUS, SE AS and BA, with only small emissions from NA and EU. Figure 2 also shows that the zonal mean of BB over 2001-2008 is generally larger in the tropics, as expected, with northern tropical regions (NAF) leading the southern tropics (SAF, SA) by approximately 8 months. Monthly mean emissions of domestic biofuel burning have a small seasonal cycle related to the heating source and are based on CO emission estimates from Streets et al. (2003), scaled by an HCN emission factor of $1.6 \%$ (Li et al., 2003). We estimate a global domestic biofuel burning HCN source 
Table 1. Geographical definitions of source regions and associated HCN annual flux estimates (Tg N/year) over 2001-2008 (biomass burning + domestic biofuel burning).

\begin{tabular}{|c|c|c|c|c|c|c|c|c|}
\hline & \multicolumn{8}{|c|}{ Geographical source regions } \\
\hline & SE AS & $\mathrm{IND}+\mathrm{AUS}$ & NAF & SAF & SA & NA & EU & BA \\
\hline $\begin{array}{l}\text { Latitude and } \\
\text { longitude definition }\end{array}$ & $\begin{array}{l}7^{\circ} \mathrm{N}-45^{\circ} \mathrm{N} \\
60^{\circ} \mathrm{E}-152^{\circ} \mathrm{E}\end{array}$ & $\begin{array}{l}50^{\circ} \mathrm{S}-7^{\circ} \mathrm{N} \\
88^{\circ} \mathrm{E}-165^{\circ} \mathrm{E}\end{array}$ & $\begin{array}{l}1^{\circ} \mathrm{S}-36^{\circ} \mathrm{N} \\
18^{\circ} \mathrm{W}-60^{\circ} \mathrm{E}\end{array}$ & $\begin{array}{l}48^{\circ} \mathrm{S}-1^{\circ} \mathrm{S} \\
5^{\circ} \mathrm{E}-60^{\circ} \mathrm{E}\end{array}$ & $\begin{array}{l}57^{\circ} \mathrm{S}-16^{\circ} \mathrm{N} \\
95^{\circ} \mathrm{W}-32^{\circ} \mathrm{W}\end{array}$ & $\begin{array}{l}16^{\circ} \mathrm{N}-88^{\circ} \mathrm{N} \\
173^{\circ} \mathrm{W}-50^{\circ} \mathrm{W}\end{array}$ & $\begin{array}{l}36^{\circ} \mathrm{N}-88^{\circ} \mathrm{N} \\
18^{\circ} \mathrm{W}-60^{\circ} \mathrm{E}\end{array}$ & $\begin{array}{l}45^{\circ} \mathrm{N}-88^{\circ} \mathrm{N} \\
60^{\circ} \mathrm{E}-180^{\circ} \mathrm{E}\end{array}$ \\
\hline $\begin{array}{l}\mathrm{HCN} \text { annual } \\
\text { emission estimate }\end{array}$ & 0.19 & 0.09 & 0.14 & 0.13 & 0.12 & 0.04 & 0.03 & 0.14 \\
\hline
\end{tabular}

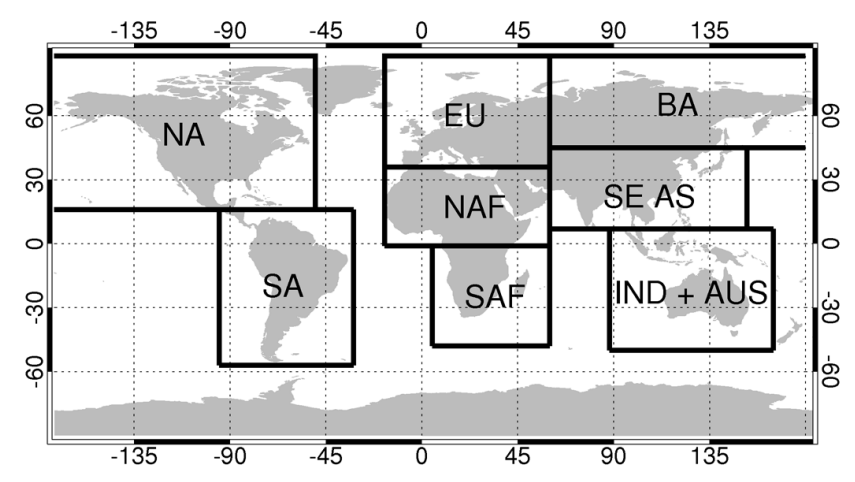

Fig. 1. Geographical source regions for the linearly decomposed HCN simulation. The regions are denoted North America (NA), South America (SA), Europe (EU), Boreal Asia (BA), North Africa (NAF), Southern Africa (SAF), Southeast Asia (SE AS), and Indonesia and Australia (IND+AUS). See Table 1 for latitude and longitude definitions and associated flux estimates.

of $0.22 \mathrm{Tg} \mathrm{N} / \mathrm{year}$, with the largest contributions from Asia (0.19 Tg N/year) and EU (0.02 Tg N/year). Table 1 shows the estimates of $\mathrm{HCN}$ emission over 2001-2008 (BB + domestic biofuel burning) from each region. Emissions over the study regions are comparable in magnitude, except over NA and $\mathrm{EU}$, where they are an order of magnitude smaller $(<50 \%$ of others); we do not investigate further NA and EU. We include the ocean uptake of HCN by air-to-sea HCN transfer flux, following Li et al. (2003). We estimate an ocean sink of $0.73 \mathrm{Tg}$ N/year, peaking in September-December due to the higher surface sea temperature (SST) in the southern hemisphere, reflecting the correlation between HCN deposition velocity over oceans and SST (Singh et al., 2003; Li et al., 2000, 2003).

The largest atmospheric sink of HCN is due to chemical reaction with $\mathrm{OH}$. We use monthly mean tropospheric $\mathrm{OH}$ fields from a full-chemistry GEOS-Chem (version 5.07.08) simulation, and use monthly mean stratospheric $\mathrm{OH}$ fields from Aura MLS v2.2 data from September 2004 to December 2008, distinguishing between day/night (for each calendar month, fields were produced for day time and night time, respectively) values (Pickett et al., 2006, 2008). The $\mathrm{HCN}+\mathrm{OH}$ reaction rate coefficient is taken from recent anal-
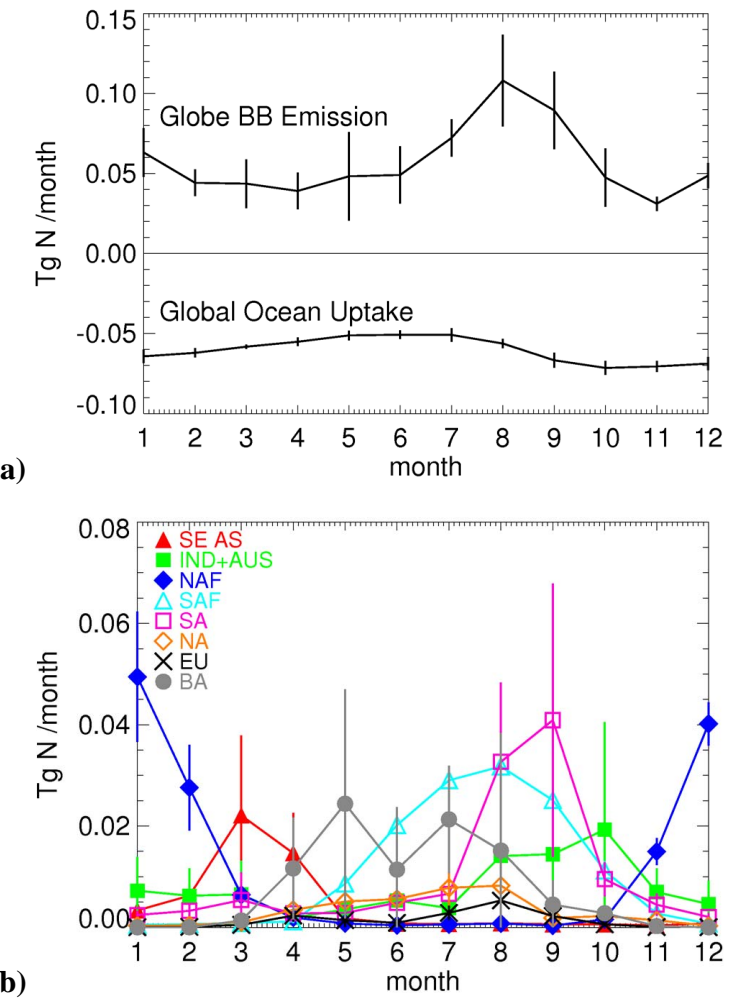

Fig. 2. Seasonal variation of global and regional mean of biomass burning sources and the ocean sink of $\mathrm{HCN}$ ( $\mathrm{Tg} \mathrm{N} /$ month) over 2001-2008. Vertical lines denote the \pm 1 -standard deviation about the mean value. Biomass burning emissions are based on GFEDv2 (van der Werf et al., 2006) and scaled by using an observed $\mathrm{HCN}$ :CO emission ratio of $0.27 \%$ (Li et al., 2003). The ocean sink parameterization follows Li et al. (2003). (a) Global emissions and ocean uptake; (b) emissions from individual regions.

ysis (Kleinboehl et al., 2006) that recommends using a value that is $40 \%$ smaller than values used in previous modelling studies (Li et al., 2003). This HCN sink represents a loss of approximately $0.12 \mathrm{Tg}$ N/year. The sink of $\mathrm{HCN}$ due to reaction with $\mathrm{O}\left({ }^{1} \mathrm{D}\right)$, the rate constant taken from Kleinboehl et al. (2006), represents a minor sink for HCN and we do not discuss this further. We also include a source of HCN from the oxidation of $\mathrm{CH}_{3} \mathrm{CN}$ by $\mathrm{OH}$, using a $30 \%$ molar yield 
(Kleinboehl et al., 2006). We acknowledge this molar yield is extremely uncertain and in Sect. 4.2 we present a sensitivity calculation that does not include this $\mathrm{HCN}$ source.

\subsection{Model evaluation}

\subsubsection{Ground-based FTIR observations}

Ground-based FTIR observations of HCN vertical columns are available at Mauna Loa, Hawaii $\left(19.5^{\circ} \mathrm{N}, 155.6^{\circ} \mathrm{W}\right.$, altitude $3.4 \mathrm{~km})$, Kitt Peak, Arizona $\left(31.9^{\circ} \mathrm{N}, 116^{\circ} \mathrm{W}\right.$, altitude $2.09 \mathrm{~km}$ ), and the Jungfraujoch research station, Switzerland $\left(46.6^{\circ} \mathrm{N}, 8.0^{\circ} \mathrm{E}\right.$, altitude $\left.3.58 \mathrm{~km}\right)$, from the Network for Detection of Atmospheric Composition Change (NDACC, http://www.ndacc.org). GEOS-Chem is sampled at the location of each station and convolved with the instrumentspecific averaging kernel (Mahieu et al., 1995, 1997; Rinsland et al., 1999, 2000, 2001, 2007).

Figure 3 shows the observed and model $\mathrm{HCN}$ total columns at the three stations between 2001 and 2008. In general, we find reasonable agreement (typical bias less than $10 \%$ ) between the model and observed HCN columns, acknowledging that at some stations the measurement coverage is sparse. Observed and model total columns of $\mathrm{HCN}$ at Jungfraujoch show a strong seasonal cycle with peaks during mid-summer and troughs during mid-winter, with model bias typically within $+3 \%$. Using our linearly decomposed $\mathrm{HCN}$ simulation over Jungfraujoch we show that the seasonal cycle is determined by NAF and BA BB. In particular, the large 2002 and 2003 fire seasons (van der Werf et al., 2006) over $\mathrm{BA}$ are captured at this location. At the lower latitude stations, Mauna Loa and Kitt Peak, the seasonal cycle is less pronounced due to the superposition of many regional burning signatures. Model bias is typically less than $+5 \%$ but can reach $+25 \%$ (e.g., Summer/Autumn 2003 over Mauna Loa). Model HCN columns over Mauna Loa and Kitt Peak have a strong intraseasonal variation, peaking in March and September. Early in the calendar year, total HCN column variations are determined by NAF, SE AS and IND+AUS. Southern hemisphere burning peaks over SAF and SA during September-October. Elevated burning during 2001 over SE AS is captured by the model and measurements over Mauna Loa.

Figure 3 also shows partial $(7-20 \mathrm{~km}) \mathrm{HCN}$ vertical columns over Jungfraujoch, which exhibit a similar but weaker seasonal cycle evident in the total columns. The model captures the broad seasonal cycle of $\mathrm{HCN}$ over this altitude range (discrepancies are typically less than $1 \%$ ), but cannot capture observed values at the peaks and troughs. Space-borne HCN data from the ACE-FTS satellite instrument (Boone et al., 2005) provides additional information over Jungfraujoch. ACE is a Canadian-led solar occultation mission launched in August 2003 into a circular orbit inclined at $74^{\circ}$ to the Equator (Bernath et al., 2005), measuring up to 30 occultations per day that mainly sample mid- and high-latitudes. The vertical resolution of ACE-FTS is 3 to $4 \mathrm{~km}$, limited by the instrument field of view. We use the ACE-FTS version 2 volume mixing ratio (vmr) profiles which aare currently available from January 2004 to August 2007. Compared to ground-based FTIR spectrometers, the ACE-FTS instrument has a lower frequency of observation at any given ground station (it crosses the Equator 8 times per year). We use the latitudinal average of ACEFTS data that fall within $41-51^{\circ} \mathrm{N}$. The interannual variations of ACE-FTS HCN are in a good qualitative agreement with the ground-based measurements but still with a positive bias of $17 \%$. The model generally reproduces the groundbased observations with a positive bias of $5 \%$. Our evaluation of the model is limited due to the lack of available groundbased data.

\subsubsection{Space-borne observations}

Satellite measurements have the major advantage of obtaining global coverage and therefore putting observed $\mathrm{HCN}$ variations at fixed stations into a broader context. For our study we use HCN retrievals from the ACE-FTS instrument (described above) and the Aura Microwave Limb Sounder (MLS). The MLS instrument (Waters, 2006) was launched in July 2004 aboard the Aura spacecraft. MLS is an emission limb sounder, operating in the millimetre and sub-millimetre spectral regions. A single day of observations consists of 3495 scans across the Earth's limb and covers all latitudes between $82^{\circ} \mathrm{S}$ and $82^{\circ} \mathrm{N}$ with a resolution of about $1.5^{\circ}$ of latitude. Successive orbits are separated by $25^{\circ}$ of longitude. MLS makes daily, global measurements of 14 trace species using 32 spectrometers distributed across five different regions of the spectrum. The $\mathrm{HCN}$ mixing ratio is retrieved from a spectrometer centred on the $177.26 \mathrm{GHz}$ spectral line. Further details can be found in Pumphrey et al. $(2006,2008)$, who note that the standard version 2.2 daily $\mathrm{HCN}$ product is noisy and has large biases in the lower stratosphere, especially in the high latitudes due to the interference of $\mathrm{HNO}_{3}$. As a result, an alternative $\mathrm{HCN}$ product was developed which has reduced noise at the cost of being available as a weekly zonal mean (Pumphrey, 2006, 2008). In this study, we use the weekly zonal mean HCN data to validate the model $\mathrm{HCN}$ mixing ratio.

Figure 4 shows zonal mean of ACE-FTS HCN concentration from September 2004 to August 2007 and the global 3-D model fields sampled at the time and location of ACEFTS data, taking into account the ACE-FTS field-of-view. The model only captures the broad features of the zonal mean distribution and generally has a negative bias (typically $\sim 15 \%$ ) in the UTLS compared with ACE-FTS. This bias is consistent with our previous comparison with groundbased FTS data that showed ACE-FTS data had a positive bias of $17 \%$ relative to ground-based column data. Figure 4 shows the model is better at capturing observed HCN temporal standard deviations $(\sigma)$, with a typical value of $\sim 10 \mathrm{pptv}$ 

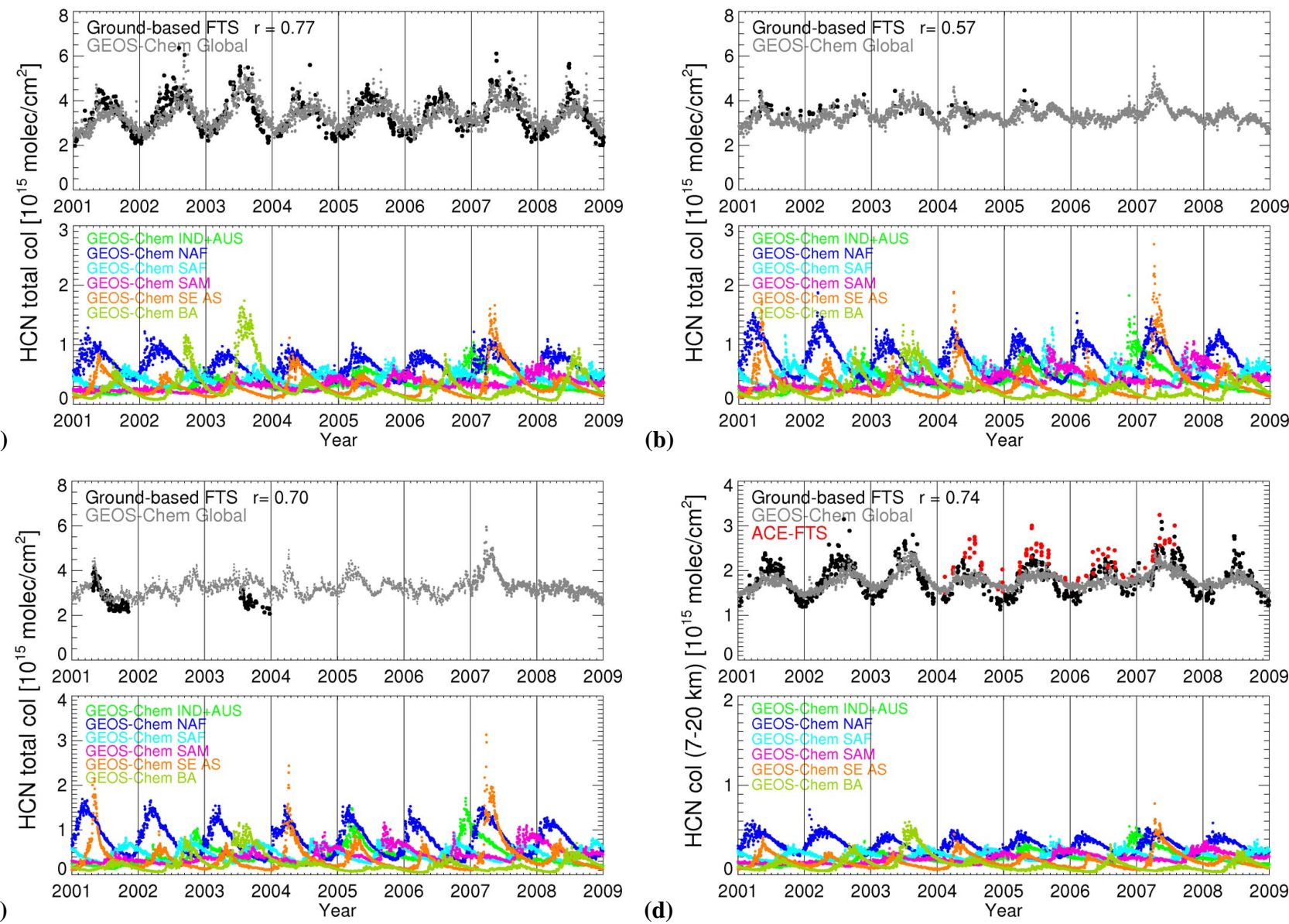

Fig. 3. Time series of FTS-observed (black dots) and GEOS-Chem model (grey dots) HCN total columns $\left(10^{15} \mathrm{molec} / \mathrm{cm}^{2}\right)$ over (a) Jungfraujoch, Switzerland $\left(46.6^{\circ} \mathrm{N}, 8.0^{\circ} \mathrm{E}\right.$, altitude $\left.3.58 \mathrm{~km}\right)$; (b) Kitt Peak, Arizona $\left(31.9^{\circ} \mathrm{N}, 116^{\circ} \mathrm{W}\right.$, altitude $\left.2.09 \mathrm{~km}\right)$; and $(\mathbf{c}) \mathrm{Mauna}$ Loa, Hawaii $\left(19.5^{\circ} \mathrm{N}, 155.6^{\circ} \mathrm{W}\right.$, altitude $\left.3.4 \mathrm{~km}\right)$. (d) shows observed and model HCN columns between $7 \mathrm{~km}$ and $20 \mathrm{~km}$ over Jungfraujoch station, with the red dots denote the latitudinal average of $\mathrm{HCN}$ columns measured by the ACE-FTS satellite instrument falling within $41^{\circ} \mathrm{N}-51^{\circ} \mathrm{N}$. Other colors denote $\mathrm{HCN}$ contributions from regional BB emissions. Vertical lines denote calendar years. The correlation coefficient $r$ denotes the correlation between measurements of HCN columns and model HCN columns; correlations $>0.1$ over Jungfraujoch, and correlations $>0.2$ over Kitt Peak and Mauna Loa, are statistically significant to the $99 \%$ confidence level.

in tropical UTLS. GEOS-Chem shows a stronger hemispherical asymmetry in the upper troposphere than ACE-FTS, suggesting an overestimate of emissions in northern hemisphere in the model. Both ACE-FTS and GEOS-Chem HCN show a low $\mathrm{HCN}$ mixing ratio in southern mid-high latitudes, implying a large ocean sink of HCN (Li et al., 2000, 2003). Figure 4 also shows model and MLS weekly zonal mean of HCN from September 2004 to December 2008. MLS measurements show a similar HCN distribution as ACE-FTS measurements show, with high mixing ratios in tropical UTLS and lower mixing ratios in mid and high latitudes. The model reproduces only the broad features of the zonal mean distribution observed by MLS, and has a larger negative bias (typically $\sim 25 \%$ ) in the tropical UTLS. As we show below, of more importance in this study is the ability of the model to accurately simulate the temporal variations of $\mathrm{HCN}$ in the UTLS as observed by MLS and ACE-FTS.

\section{Model and observed variability of $\mathrm{HCN}$ in the troposphere and stratosphere}

Atmospheric transport from the troposphere to the stratosphere generally plays an important role in the atmospheric distribution of trace gases. Over the tropics, deep convection via cumulonimbus clouds reaching the UTLS and large-scale ascent via the major upward branch of the Brewer-Dobson (BD) circulation in the stratosphere represent the dominant vertical transport processes. For trace gases over the tropics with an atmospheric lifetime longer than the transit time from the tropopause to the mid-stratosphere, a clear upward transport of the signal of seasonal cycle is called the "atmospheric tape recorder" (Mote et al., 1996). For $\mathrm{H}_{2} \mathrm{O}$, there is a clear annual tape recorder effect (Mote et al., 1996) in the tropical UTLS. For CO, the annual tape recorder is also observed below $20 \mathrm{~km}$ (Schoeberl et al., 2006). However, a recent 

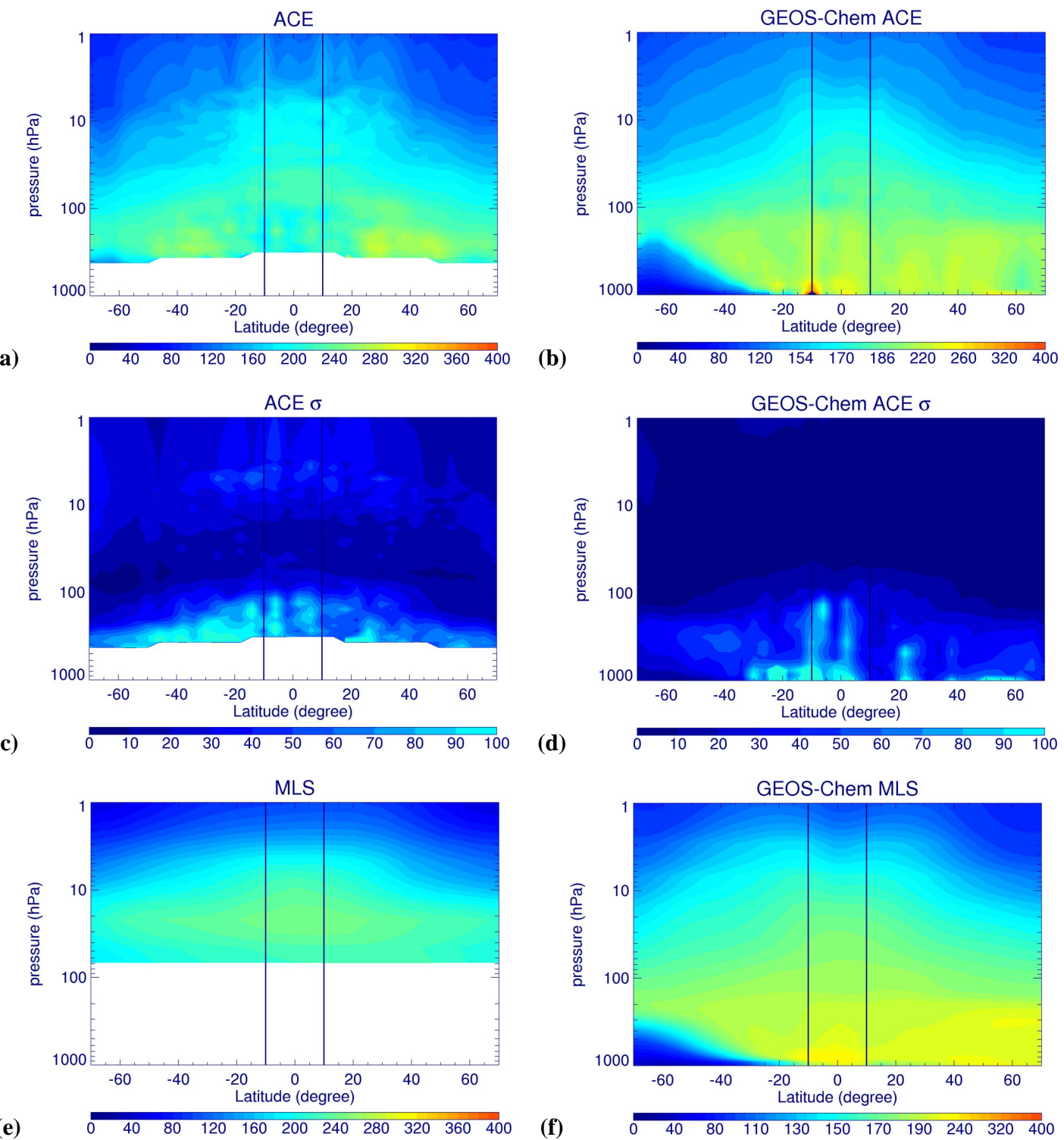

(e)

MLS $\sigma$

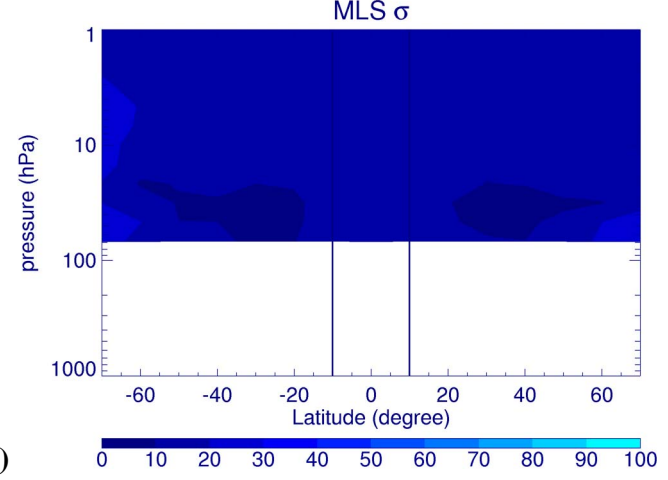

(f)

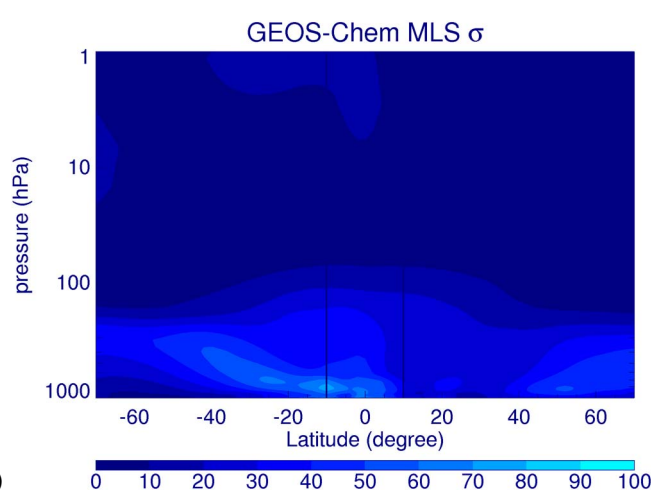

Fig. 4. GEOS-Chem model and observed zonal mean distributions of HCN (pptv) and associated standard deviations (pptv) as a function of pressure $(\mathrm{hPa})$. The GEOSChem model, run at $2^{\circ} \times 2.5^{\circ}$ horizontal resolution, is sampled at the time and location of each observed scene. (a) and (b) show zonal mean HCN distributions from the Atmospheric Chemistry Experiment (ACE) and the GEOS-Chem model from 1 September 2004 to 31 August 2007; and (c) and (d) show the corresponding standard deviations from those mean values. (e) and (f) show zonal mean HCN distributions from the Microwave Limb Sounder (MLS) and from GEOS-Chem from 1 September 2004 to 31 December 2008; and (g) and (h) show the corresponinding standard deviations from those mean values. We use weekly zonal mean MLS products (Pumphrey et al., 2008). The two vertical lines define the tropical region $\left(10^{\circ} \mathrm{S}-10^{\circ} \mathrm{N}\right)$ over which the $\mathrm{HCN}$ anomalies are calculated. 
analysis of HCN anomalies from Aura MLS and ACE-FTS instruments showed an approximate 2-year cycle (Pumphrey et al., 2008), and it was suggested that this was partly due to the year-to-year variability in BB emissions over Indonesia and Australia.

We determine HCN anomalies, defined here as the fluctuation from the time mean, from ACE-FTS and MLS data and the GEOS-Chem model. Model HCN anomalies are calcuated by sampling the model in the same way as MLS and ACE-FTS sample the real atmosphere. Figure 5 shows that model $\mathrm{HCN}$ anomalies in the troposphere alternate between positive and negative on a 12-month cycle, with the positive anomalies occurring from September to January and negative anomalies from February to August. These positive anomalies correspond to the peaks of BB emissions from tropical regions of IND + AUS, SA and NAF in September to January as shown in Fig. 2. Figure 5 shows that there is remarkable agreement at the UTLS between model HCN anomalies in the troposphere and MLS and ACE-FTS HCN anomalies in the UTLS (with a typical bias of only $3 \%$ ). This suggests that the model and measured $\mathrm{HCN}$ anomalies are consistent, and using the GEOS-Chem model as an intermediary implies that the ground-based FTS data are consistent with MLS and ACE-FTS. However, the contour lines for the GEOS-Chem HCN slope upwards more steeply than those for the observed mixing ratios, implying that vertical transport in the model is faster than in the real atmosphere, particularly at altitudes above $30 \mathrm{hPa}$ (Figs. 10 and 11 of Schoeberl et al., 2008). Due to the limited time resolution of ACE-FTS instrument, we smooth the ACE-FTS data in time to retrieve the continuous tape recorder of $\mathrm{HCN}$. We use a kernel smoothing technique (Wand and Jones, 1995) with a bandwidth of 0.2 years. Consequently, seasonal variations of $\mathrm{HCN}$ in the troposphere (peaks in February/September and troughs in June/November), and similar stratospheric variations but with a month lag, observed by MLS are not well captured by ACE-FTS. The 2-year cycle in the lower stratosphere is still reproduced by the smoothed ACE data.

Figure 5 also shows the tape recorder of $\mathrm{HCN}$ retrieved from the MLS standard version 2.2 daily products. Although as we indicated in last section the zonal mean values of MLS standard daily $\mathrm{HCN}$ concentration products are generally not recommended for use in the lower stratosphere (Pumphrey et al., 2008), we find that HCN anomalies of MLS standard products agree with MLS weekly zonal mean products over the equatorial regions. We restrict our analysis to equatorial regions where the interferences of $\mathrm{HCN}$ due to $\mathrm{HNO}_{3}$ is small.

We conducted the HCN simulation for a 8-year period (January 2001-December 2008), allowing us to put the relatively short ACE (used from September 2004 to August 2007) and MLS (used from September 2004 to December 2008) record into a broader temporal perspective. Figure 6 shows that our results over the ACE-FTS and Aura MLS time period are consistent with the 8-year model
Table 2. The 2001-2008 mean percentage contribution of regional biomass burning emissions to the global and stratosphere HCN budgets.

\begin{tabular}{|c|c|c|c|c|c|c|c|}
\hline & \multicolumn{7}{|c|}{ Biomass burning regions } \\
\hline & $\begin{array}{l}\text { IND + } \\
\text { AUS }\end{array}$ & NAF & SAF & SA & SE AS & BA & $\begin{array}{l}\text { Other } \\
\text { regions }\end{array}$ \\
\hline $\begin{array}{l}\text { Contribution } \\
(\%) \text { to } \\
\text { global } \\
\text { HCN budget }\end{array}$ & 10.4 & 15.8 & 14.6 & 13.0 & 6.8 & 10.9 & 6.3 \\
\hline $\begin{array}{l}\text { Contribution } \\
(\%) \text { to } \\
\text { tropical } \\
\text { stratospheric } \\
\text { HCN budget }\end{array}$ & 13.0 & 19.5 & 14.3 & 11.8 & 9.9 & 4.8 & 2.9 \\
\hline
\end{tabular}

calculation that encompasses approximately four 2-year cycles in the LS. Recent analysis of variability of MLS HCN measurements suggested the variations of surface burning in Indonesia and Australia might contribute to the 2-year variations of HCN in the LS (Pumphrey et al., 2008). It has not escaped our attention that other sources of atmospheric variability in the tropical UTLS (e.g., Quasi-Biennial Oscillation, the QBO, shown in Fig. 6) may also play a role in determining the 2-year cycle. In the next section we investigate the role of atmospheric dynamics and regional $\mathrm{BB}$ emisions on determining the tropical variation of $\mathrm{HCN}$ through a sensitivity analysis of the model results.

Table 2 shows the 2001-2008 mean percentage contribution of regional $\mathrm{BB}$ emissions to the global $\mathrm{HCN}$ budget and to the tropical stratospheric HCN budget. We find the largest contributions to the global budget are from IND + AUS, NAF, SAF, SA, and BA, all representing more than $10 \%$. The largest stratospheric contributions are from IND + AUS, NAF, SAF, and SA, again all representing more than $10 \%$. We find the increased stratospheric percentage contributions from individual $\mathrm{HCN}$ budget terms compared to the global values are from IND + AUS, NAF and SE AS, corresponding to the active tropical convective regions (Liu et al., 2005). BB emissions represent approximately $80 \%$ of tropical stratospheric $\mathrm{HCN}$, with the remainder from domestic biofuel and from the oxidation of $\mathrm{CH}_{3} \mathrm{CN}$ (Sect. 2).

\section{Sensitivity of results to biomass burning, dynamics and atmospheric chemistry}

In this section we investigate how sensitive model $\mathrm{HCN}$ anomalies are to changes in our assumptions about atmospheric dynamics, biomass burning and atmospheric chemistry. 
(a)
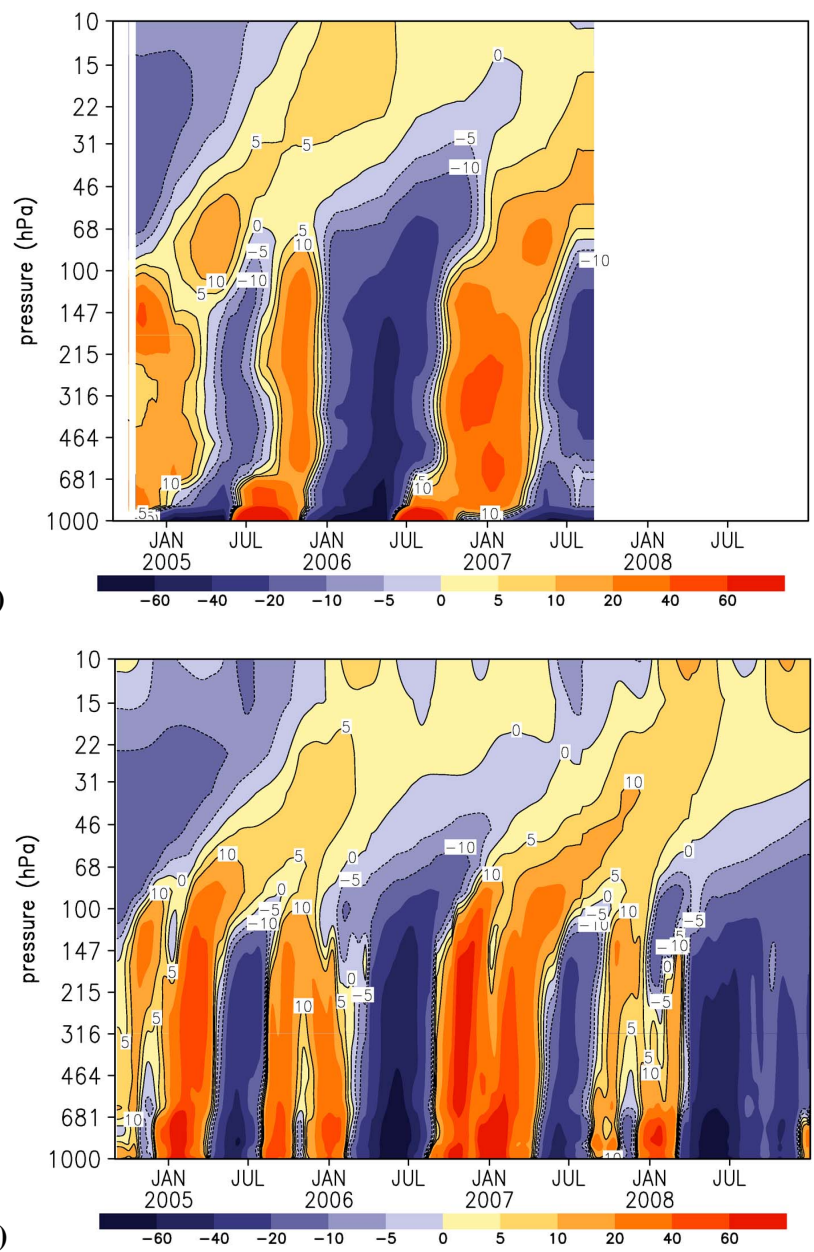

(b)

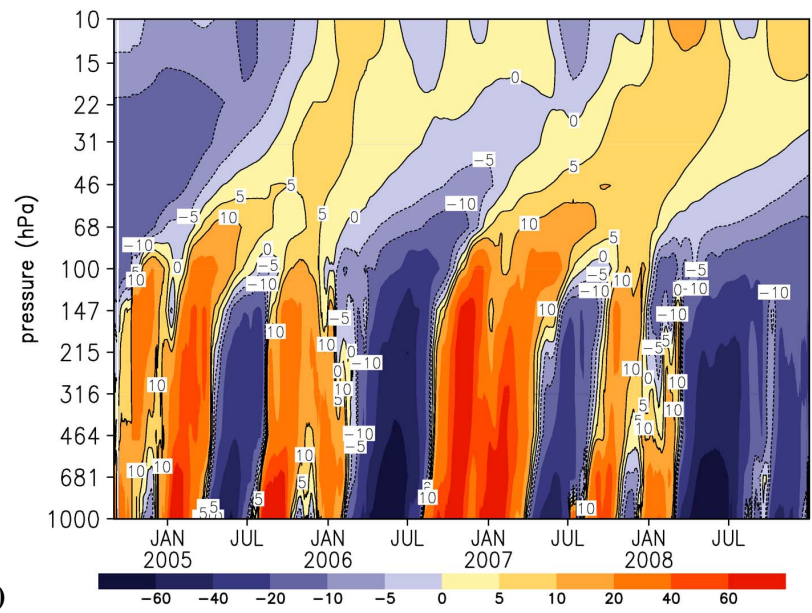

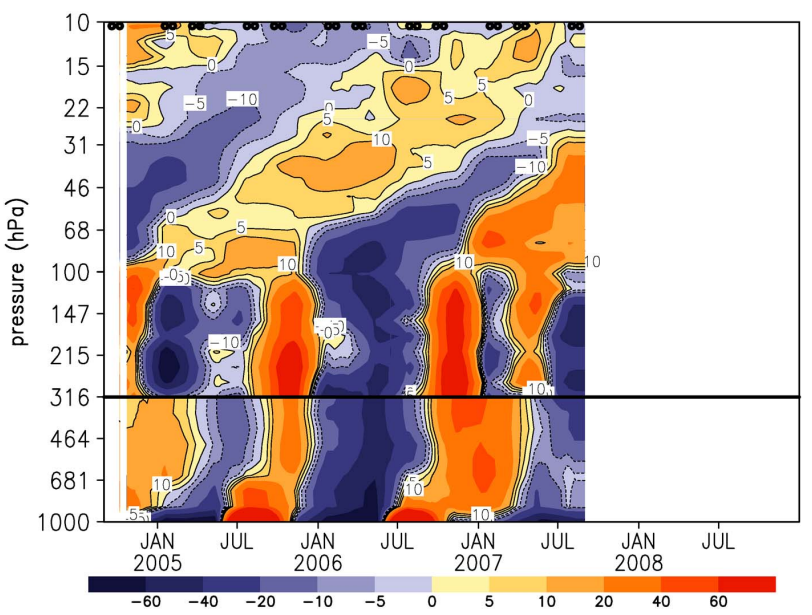

(d)

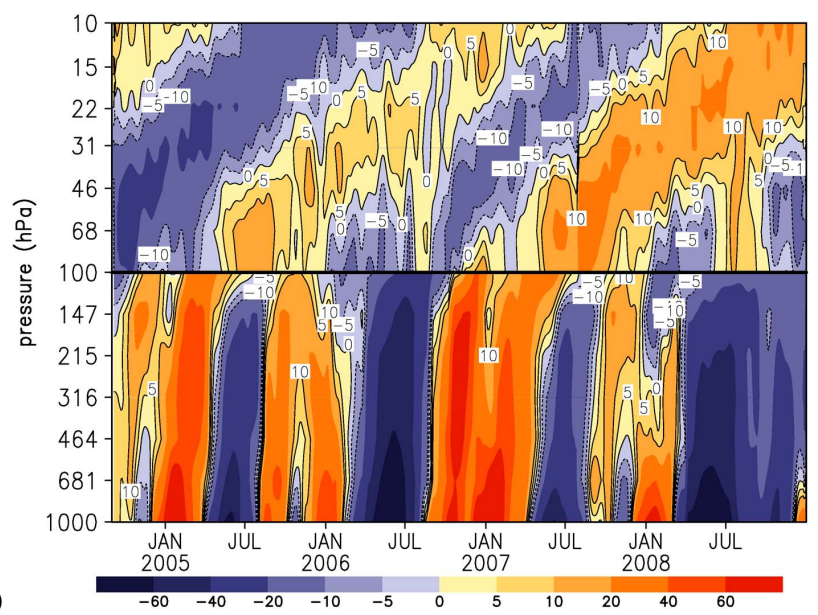

(e)

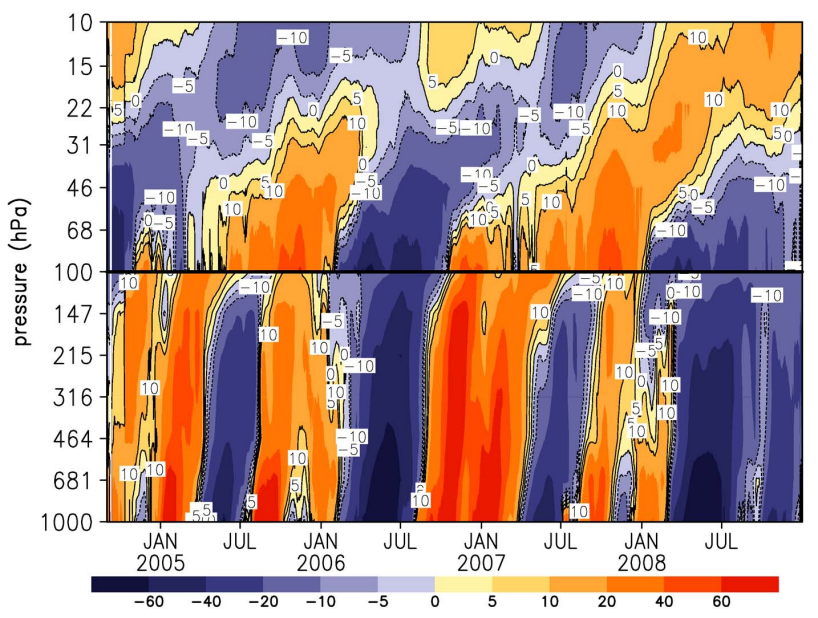

Fig. 5. GEOS-Chem model and observed HCN (pptv) tropical anomalies $\left(10^{\circ} \mathrm{S}-10^{\circ} \mathrm{N}\right)$ as a function of pressure (hPa). The GEOS-Chem model, run at $2^{\circ} \times 2.5^{\circ}$ horizontal resolution, is sampled at the time and location of each observed scene. Model HCN anomalies as observed by (a) ACE-FTS, (b) MLS weekly zonal mean products (Pumphrey et al., 2008), and (c) MLS version 2.2 standard daily products. Model $\mathrm{HCN}$ anomalies (pptv) as observed by (d) ACE-FTS with observed anomalies superimposed from $316 \mathrm{hPa}-10 \mathrm{hPa}$, (e) MLS weekly zonal mean with observed anomalies superimposed from $100 \mathrm{hPa}-10 \mathrm{hPa}$, and (f) MLS standard daily mean with observed anomalies superimposed from $100 \mathrm{hPa}-10 \mathrm{hPa}$. Circles in (d) indicate the times at which ACE-FTS makes measurements within $10^{\circ} \mathrm{S}-10^{\circ} \mathrm{N}$. 


\subsection{Role of atmospheric dynamics and biomass burning sources}

Figure 6 showed that the tape recorder effect of model HCN between 2001 and 2008 encompassed approximately four 2year cycles in the lower stratosphere. To isolate the influence of dynamics and $\mathrm{BB}$ emissions on variations in $\mathrm{HCN}$, we calculate $\mathrm{HCN}$ anomalies using a single year of meteorology (2006 in this study) or BB emissions (2001 in this study), respectively, eliminating the effect of year-to-year variations in atmospheric transport or BB emissions, respectively. Figure 7 shows highest correlations between BB emissions and variability of $\mathrm{HCN}$ over the tropical troposphere and lower/mid-troposphere, suggesting that surface $\mathrm{BB}$ emissions are the primary driving factor for observed $\mathrm{HCN}$ variability in the troposphere and lower stratosphere. Surface emissions from Africa, Indonesia and Australia contribute the most to both the magnitude (Table 2) and variability of $\mathrm{HCN}$ over this vertical region. Figure 7 shows the year to year changes in meteorology (e.g., QBO) play a larger role in determining $\mathrm{HCN}$ variability in the upper stratosphere. Further investigation is required but this is outside the scope of this study.

So why during some years is $\mathrm{HCN}$ anomalously high in the lower stratosphere? Figure 8 suggests that both the magnitude of the emissions and the length of burning seasons play a role. Here, we have identified monthly emissions that are greater than the 2001-2008 mean (denoted by red triangles) as a crude measure of peak burning months that determine the burning season; anomalous burning months (denoted by blue squares) are 2.5 times greater than the mean. The African burning season, according to GFEDv2 estimates (van der Werf et al., 2006), is more regular in magnitude (peaking in late/early months) and timing than burning seasons from other continents, reflected in the contribution of atmospheric $\mathrm{HCN}$ from Africa BB emissions. Based on the small number of complete burning seasons, the only two common characteristics for anomalous high $\mathrm{HCN}$ concentrations in the UTLS $(2002 / 2003,2004 / 2005,2005 / 2006$, $2006 / 2007,2007 / 2008$ ) is 1) larger than normal emissions and 2) longer burning seasons from IND + AUS and/or SA. We acknowledge that the duration of the burning season and the magnitude of emissions may be interrelated. During 2002/2003 and 2006/2007, BB emissions over IND + AUS are particularly high (Fig. 8), resulting in anomalously high contributions to atmospheric $\mathrm{HCN}$ in late 2002 and late 2006 (Fig. 7), that begin to overlap in time with lofted African airmasses. During 2004/2005, the burning season over IND + AUS was longer than normal (Fig. 8) and BB emissions over SA were anomalously large (Fig. 8). This resulted in anomalously high $\mathrm{HCN}$ contributions from both regions, overlapping in time with lofted African airmasses. During 2005/2006 and 2007/2008, anomalously high BB emissions from SA (Fig. 8) provide similar contributions to the $\mathrm{HCN}$

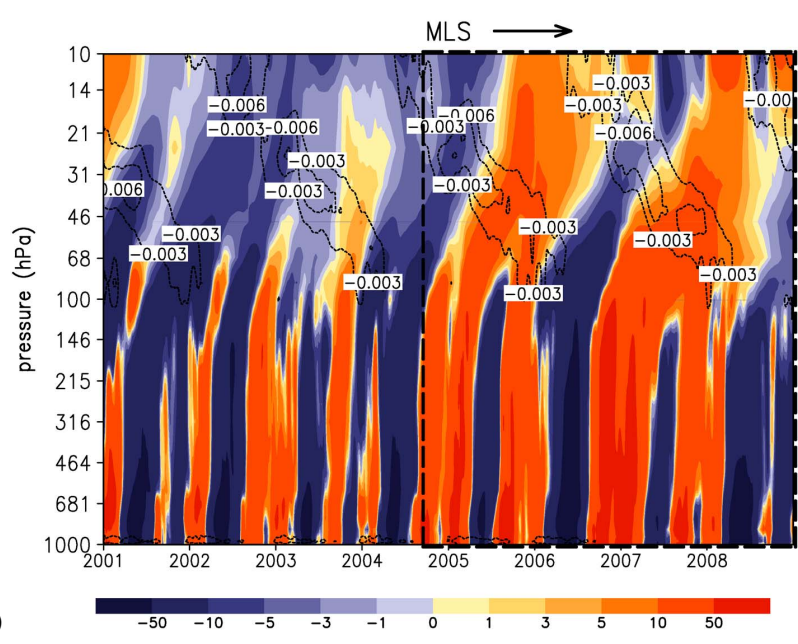

(a)
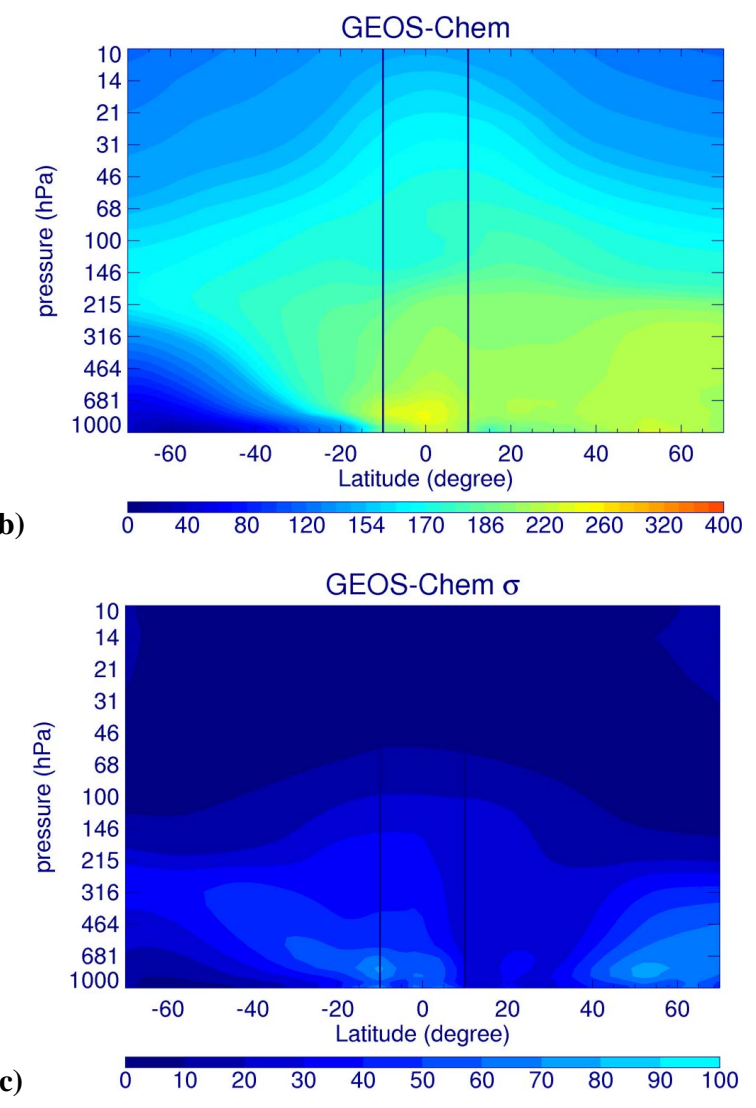

Fig. 6. (a) GEOS-Chem model tropical $\left(10^{\circ} \mathrm{S}-10^{\circ} \mathrm{N}\right) \mathrm{HCN}$ anomalies (pptv) between 2001 and 2008. Contours denote negative values of the tropical zonal mean wind shear $\left(\mathrm{s}^{-1}\right)$, a proxy for the QBO determined using GEOS-4 (2001-2003) and GEOS-5 (2004-2008) meteorology. The dashed lines denote the Aura MLS observing time period (1 September 2004-31 December 2008). (b) Zonal mean of GEOS-Chem HCN concentrations (pptv) between 2001 and 2008, and (c) its standard deviation. Vertical lines define the tropical region $\left(10^{\circ} \mathrm{S}-10^{\circ} \mathrm{N}\right)$ over which the $\mathrm{HCN}$ anomalies are calculated. 

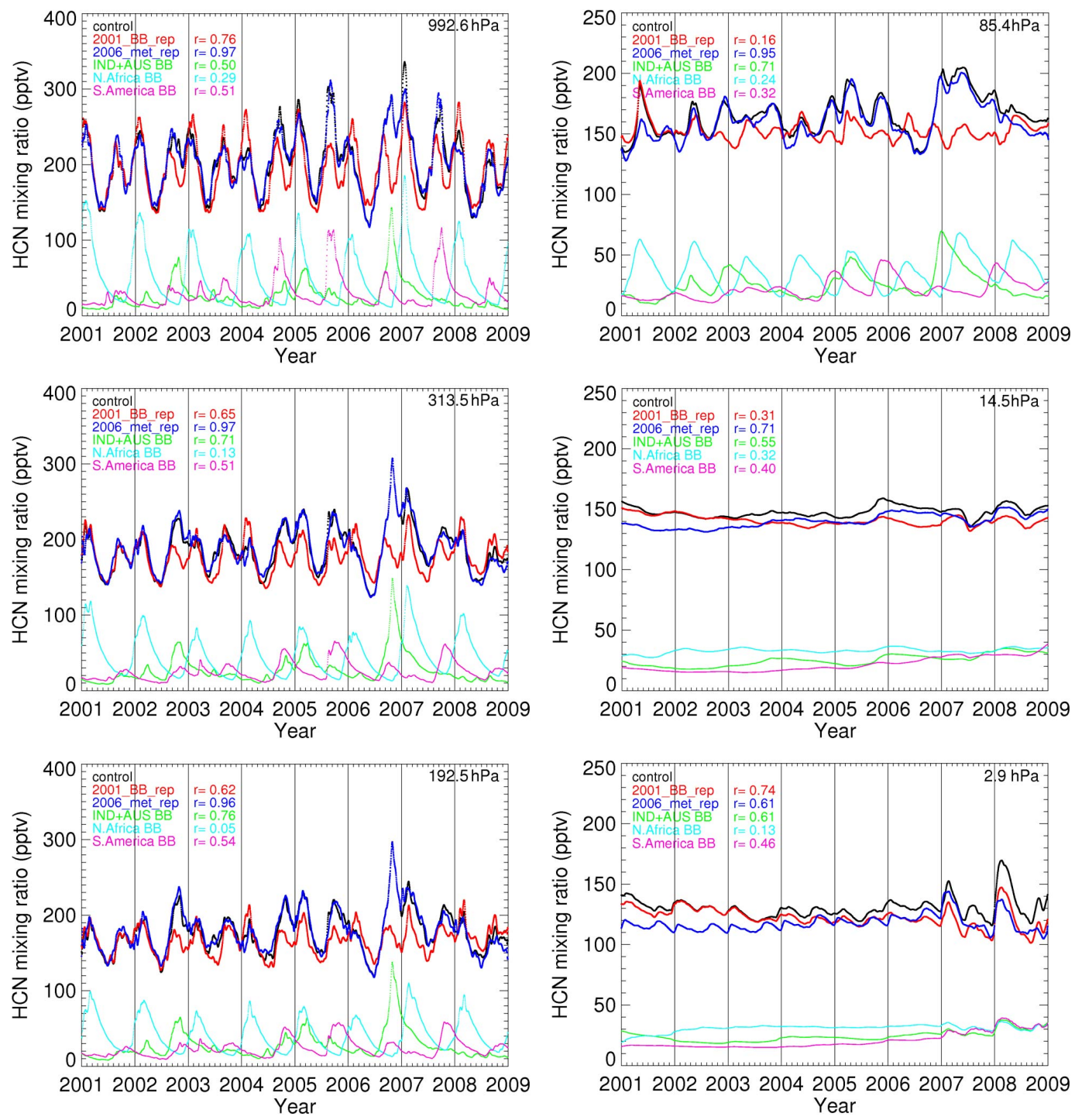

Fig. 7. GEOS-Chem HCN mixing ratios (pptv) averaged between $10^{\circ} \mathrm{S}-10^{\circ} \mathrm{N}$ during $2001-2008$ in the troposphere (left panels) and the stratosphere (right panels): control experiment (black line); constant $2001 \mathrm{BB}$ emissions experiment (red line); and constant 2006 meteorology experiment (dark blue line). Other colors denote HCN contributions from regional BB emissions: IND+AUS (green line), NAF (light blue line), and SA (purple line). The correlation coefficient $r$ denotes the correlation between HCN mixing ratios and the total HCN mixing ratio of the control experiment; correlations $>0.1$ are statistically significant to the $99 \%$ confidence level.

budget in the lower and mid-troposphere than emissions from Africa (Fig. 7), resulting in anomalously large $\mathrm{HCN}$ concentrations. The temporal overlapping of comparatively regular African BB emissions and emissions from other continents is key in establishing the apparent biennial cycle of HCN in the UTLS. This is consistent with Duncan et al. (2007) who showed that year-to-year of BB pollution in the UTLS are explained by year-to-year changes in BB from from Indonesia (here included in IND + AUS) and Central America (here included in SA), particularly during El Niño years when widespread fires occur over these regions.

Why is this transition between annual and biennial variations not observed in other trace gases? This is probably due to the atmospheric lifetime of the tracer being studied. For $\mathrm{CO}$, with an atmospheric lifetime much less than $\mathrm{HCN}$, especially in the stratosphere, the signals due to surface emissions are too weak in the LS. For HCN, using the similar surface emission sources and ocean uptake sinks following $\mathrm{Li}$ et al. (2003), with the atmospheric sources of yields of $\mathrm{CH}_{3} \mathrm{CN}+\mathrm{OH}$ (Kleinboehl et al., 2006) (see below) and atmospheric sinks of chemical reactions with $\mathrm{OH}$ and $\mathrm{O}\left({ }^{1} \mathrm{D}\right)$, our model suggests a lifetime of 6.1 months. With this lifetime, the model reproduced the approximate 2-year cycle of $\mathrm{HCN}$ in the UTLS as observed by MLS and ACE-FTS, implying that our model source and sink estimates for $\mathrm{HCN}$ are appropriate. 


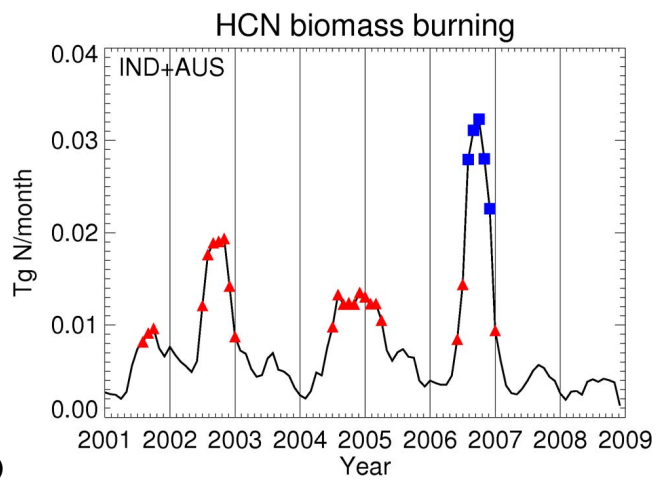

(a)

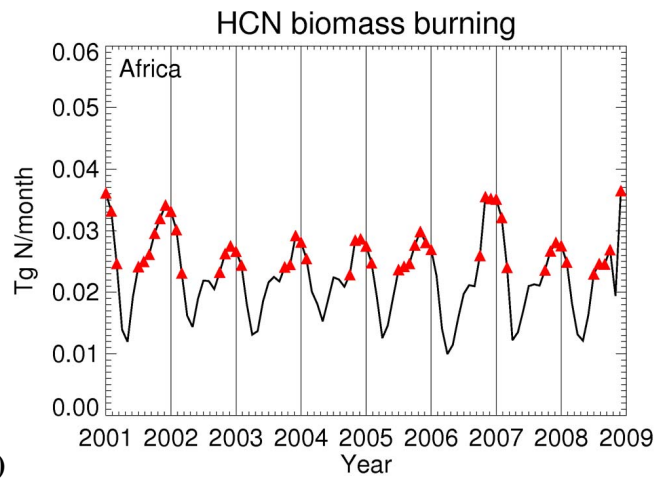

(b)

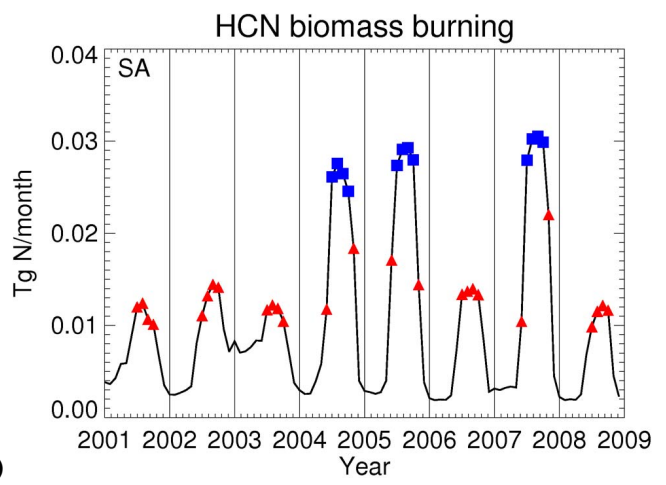

Fig. 8. Time series (solid line) of HCN biomass burning emission (Tg N/month) between 2001 and 2008 over (a) IND + AUS; (b) Africa (NAF + SAF); and (c) SA. Emissions above the 2001-2008 mean value are denoted by red triangles, and emissions 2.5 times above this mean value are denoted by blue squares. Emissions are based on GFEDv2 (van der Werf et al., 2006) and scaled using an observed HCN:CO emission ratio of $0.27 \%$ (Li et al., 2003). Vertical lines denote calendar years.

\subsection{The $\mathrm{HCN}$ source from $\mathrm{CH}_{3} \mathrm{CN}+\mathrm{OH}$}

As discussed above, our quantitative understanding of the $\mathrm{HCN}$ source from the oxidation of $\mathrm{CH}_{3} \mathrm{CN}$ by $\mathrm{OH}$ is incomplete (Kleinboehl et al., 2006 and references therein). In our control simulation we used a $30 \%$ molar $\mathrm{HCN}$ yield that reconciled model calculations and balloon measurements at mid and high latitudes (Kleinboehl et al., 2006). This atmo- spheric source of $\mathrm{HCN}$ is generally small in the troposphere $(<1 \%$ of total $\mathrm{HCN}$ concentrations) but plays a larger role in the stratosphere (typically 5\%), particularly at high latitudes $(>7 \%)$. We find that including this $\mathrm{HCN}$ source does help to decrease $(\sim 25 \%)$ the discrepancy between model and ACEFTS observed HCN concentrations in the stratosphere (figure not shown) but does not improve further the model ability to capture observed $\mathrm{HCN}$ variations.

\section{Concluding remarks}

We have interpreted observed variations of $\mathrm{HCN}$ in the troposphere and lower stratosphere using the GEOS-Chem global 3-D model of atmospheric chemistry and transport. We found that the observed annual and semi-annual variations in column $\mathrm{HCN}$ at three ground-based stations at low and mid-latitudes are described by the model with a positive bias of 5\%. Using GEOS-Chem, we find that these variations are largely determined by biomass burning, with a number of superimposed regional burning signals in tropical latitudes. Using HCN measurements from ACE-FTS and MLS, we found that in the UTLS the dominant period of variability is close to 24 months. We find this is true for the 36-month record from ACE-FTS and for the 52-month record from MLS which overlap our GEOS-Chem simulation. Using GEOS-Chem, we were able to reproduce only the broad observed distribution of HCN concentration typically with a negative bias of $20 \%$, and the observed distribution of standard deviations of $\mathrm{HCN}$ concentrations with a similar value of $\sim 10 \mathrm{pptv}$ in tropical UTLS, and the observed tropical variability typically with a negative bias of 7\%, compared with the satellite observations over the 52 months. Putting that observation period into a longer temporal perspective, by inspecting model variability from the previous four years, we observe a strong variability on a timescale of 24 months in the lower stratosphere.

We find that tropical biomass burning is the largest single source of $\mathrm{HCN}$ and represents most of variability in the UTLS over the tropics, with the remainder of the variability due to atmospheric transport processes. Linking the quasibiennial oscillation (QBO) and the UTLS HCN distribution is outside the scope of this study. We find that the extent of temporal overlap between African BB emissions and those from other continents, particular Indonesia, Australia and South America, is key in establishing the apparent biennial cycle in the UTLS. Transition from the annual and semiannual variations of trace gases in the upper troposphere to the 2-year variation in the lower stratosphere has not been observed previously, perhaps due to the shorter lifetime of the other trace gases studied.

The main objective of this paper was to develop HCN as a reliable tracer for biomass burning, which we could then use to quantify BB emissions thereby helping to constrain other sources. Without first reconciling the apparent 
discrepancy between available observations it would be difficult to achieve that objective. Using a global 3-D chemistry transport model was key in achieving this reconciliation. The model was able to reproduce the magnitude and variability of observed column concentrations over a limited number of available ground stations. GEOS-Chem was only able to reproduce the broad scale features of the $\mathrm{HCN}$ distributions observed by ACE-FTS and MLS but it successfully reproduced the timing and magnitude of observed fluctuations of $\mathrm{HCN}$ in the upper troposphere and lower stratosphere, reflecting the model ability to simulate atmospheric transport. Reducing the discrepancy between model and observed HCN concentrations will require better constraints on the surface emissions and also on the atmospheric chemistry. We acknowledge that using upper tropospheric measurements of $\mathrm{HCN}$ to infer other sources will be difficult without better constraints on the rest of the troposphere. However, these observations provide information about mechanisms of stratospheretroposphere exchange (STE) of air and its origin, particularly if they are used in conjunction with concurrent measurements of $\mathrm{CO}$ and $\mathrm{O}_{3}$ which we will explore in future work.

Acknowledgements. This work is funded by the UK Natural Environmental Research Council (NERC) under NE/E003990/1. The ground-based FTIR data of HCN from Kitt Peak and Mauna Loa stations were provided by the NDACC network (http://www.ndacc.org). The ACE mission is primarily funded by the Canadian Space Agency. The ground-based FTIR data of HCN from Jungfraujoch station were provided by University of Liège. Primarily supported by the Belgian Federal Science Policy Office (PRODEX and SSD programs), Brussels. We acknowledge the International Foundation High Altitude Research Stations Jungfraujoch and Gornergrat (HFSJG, Bern, Switzerland) for allowing us to conduct our experiments at the High Altitude Research Station at Jungfraujoch. We also thank our colleagues from Harvard University who developed the GEOS-Chem capability of using GEOS-5 meteorology.

Edited by: B. N. Duncan

\section{References}

Baldwin, M. P., Gray, L. J., and Dunkerton, T. J.: The quasi-biennial oscillation, Rev. Geophys., 39, 179-229, 2001.

Bange, H. W. and Williams, J.: Acetonitrile in atmospheric and biogeochemical cycles, Atmos. Environ., 34, 4959-4990, 2000.

Bernath, P. F., McElroy, C. T., Abrams, M. C., et al.: Atmospheric Chemistry Experiment (ACE): Mission overview, Geophys. Res. Lett., 32, L15S01, doi:10.1029/2005GL022386, 2005.

Bertschi, I., Yokelson, R. J., Ward, D. E., Babbitt, R. E., Susott, R. A., Goode, J. G., and Hao, W. M.: Trace gas and particle emissions from fires in large diameter and belowground biomass fuels, J. Geophys. Res., 108(D13), 8472, doi:10.1029/2002JD002100, 2003.

Bey, I., Jacob, D. J., Yantosca, R. M., Logan, J. A., Field, B. D., Fiore, A. M., Li, Q., Liu, H. Y., Mickley, L. J., and Schultz, M. G.: Global modeling of tropospheric chemistry with assim- ilated meteorology: Model description and evaluation, J. Geophys. Res., 106(D19), 23073-23095, 2001.

Boone, C. D., Nassar, R., Walker, K. A., Rochon, Y., McLeod, S. D., Rinsland, C. P., and Bernath, P. F.: Retrievals for the atmospheric chemistry experiment Fourier-transform spectrometer, Appl. Optics, 44, 7218-7231, 2005.

Brasseur, G., Zellner, De Rudder, R. A., and Arjis, E.: Is hydrogen cyanide a progenitor of acetonitrile in the atmosphere?, Geophys. Res. Lett., 12, 117-120, 1985.

Cicerone, R. J. and Zellner, R.: The Atmospheric Chemistry of Hydrogen Cyanide (HCN), J. Geophys. Res., 88(C15), 10689 10696, 1983.

Duncan, B. N., Strahan, S. E., Yoshida, Y., Steenrod, S. D., and Livesey, N.: Model study of the cross-tropopause transport of biomass burning pollution, Atmos. Chem. Phys., 7, 3713-3736, 2007, http://www.atmos-chem-phys.net/7/3713/2007/.

Fiore, A., Jacob, D. J., Liu, H., Yantosca, R. M., Fairlie, T. D., and Li, Q. B.: Variability in surface ozone background over the United States: Implications for air quality policy, J. Geophys. Res., 108(4787), doi:10.1029/2003JD003855, 2003.

Holton, J. R., Haynes, P. H., McIntyre, M. E., Douglass, A. R., Rood, R. B., and Pfister, L.: Stratosphere-Troposphere Exchange, Rev. Geophys., 33(4), 403-439, 1995.

Holzinger, R., Warneke, C., Hansel, A., Jordan, A., and Lindinger, W.: Biomass burning as a source of formaldehyde, acetaldehyde, methanol, acetone, acetonitrile, and hydrogen cyanide, Geophys. Res. Lett., 26(8), 1161-1164, 1999.

Holzinger, R., Jordan, A., Hansel, A., and Lindinger, W.: Automobile emissions of acetonitrile: Assessments of its contribution to the global sources, Atmos. Environ., 38, 187-193, 2001.

Jacob, D. J., Crawford, J., Kleb, M. M., Connors, V. S., Bendura, R. J., Raper, J. L., Sachse, G. W., Gille, J., Emmons, L., and Heald, J. C.: Transport and Chemical Evolution over the Pacific (TRACE-P) mission: Design, execution, and first results, J. Geophys., Res., 108(D20), 9000, doi:10.1029/2002JD003276, 2003.

Kleinboehl, A., Toon, G. C., Sen, B., et al.: On the stratospheric chemistry of hydrogen cyanide, Geophys. Res. Lett., 33, L11806, doi:10.1029/2006GL026015, 2006.

Li, Q., Jacob, D. J., Bey, I., Yantosca, R. M., Zhao, Y., Kondo, Y., and Notholt, J.: Atmospheric hydrogen cyanide ( $\mathrm{HCN})$ : Biomass burning source, ocean sink?, Geophys. Res. Lett., 27(3), 357360, 2000.

Li, Q., Jacob, D. J., Yantosca, R. M., Heald. C. L., Singh, H. B., Koike, M., Zhao, Y., Sachse, G. W., and Streets, D. G.: A global three-dimensional model analysis of the atmospheric budgets of $\mathrm{HCN}$ and $\mathrm{CH}_{3} \mathrm{CN}$ : Constraints from aircraft and ground measurements, J. Geophys. Res., 108(D21), 8827, doi:10.1029/2002JD003975, 2003.

Liu, C. and Zipser, E. J.: Global distribution of convection penetrating the tropical tropopause, J. Geophys. Res., 110, D23104, doi:10.1029/2005JD006063, 2005.

Lobert, J. M., Scharffe, D. H., Hao, W. M., and Crutzen, P. J.: Importance of biomass burning in the atmospheric budgets of nitrogen-containing gases, Nature, 346, 552-554, 1990.

Logan, J. A., Jones, D. B. A., Megretskaia, I. A., et al.: Quasibiennial oscillation in tropical ozone as revealed by ozonesonde and satellite data, J. Geophy. Res., 108(D8), 4244, doi:1029/2002JD002170, 2003. 
Lupu, A., Kaminski, J. W., Neary, L., McConnell, J. C., Toyota, K., Rinsland, C. P., Bernath, P. F., Walker, K. A., Boone, C. D., Nagahama, Y., and Suzuki, K.: Hydrogen cyanide in the upper troposphere: GEM-AQ simulation and comparison with ACEFTS observations, Atmos. Chem. Phys., 9, 4301-4313, 2009, http://www.atmos-chem-phys.net/9/4301/2009/.

Mahieu, E., Rinsland, C. P., Zander, R., Demoulin, P., Delbouille, L., and Roland, G.: Vertical Column Abundances of HCN Deduced from Ground-Based Infrared Solar Spectra: Long-Term Trend and Variability, J. Atmos. Chem., 20, 299-310, 1995.

Mahieu, E., Zander, R., Delbouille, L., Demoulin, P., Roland, G., and Servais, C.: Observed trends in total vertical column abundances of atmospheric gases from IR solar spectra recorded at the Jungfraujoch, J. Atmos. Chem., 28, 227-243, 1997.

Martin, R. V., Jacob, D. J., Logan, J. A., et al.: Interpretation of TOMS observations of tropical tropospheric ozone with a global model and in situ observations, J. Geosphys. Res., 107(D18), 4351, doi:10.1029/2001JD001480, 2002.

Mote, P. W., Rosenlof, K. H., McIntyre, M. E., et al.: An atmospheric tape recorder: The imprint of tropical tropopause temperatures on stratospheric water vapor, J. Geophys. Res, 101(D2), 3989-4006, 1996.

Park, R. J., Jacob, D. J., Field, B. D., Yantosca, R. M., and Chin, M.: Natural and transboundary pollution influences on sulface-nitrate-ammonium aerosols in the United States: Implications for policy, J. Geophys. Res., 109, D15204, doi:10.1029/2003JD004473, 2005.

Pickett, H. M., Read, W. G., Lee, K. K., and Yung, Y. L.: Observation of night $\mathrm{OH}$ in the mesosphere, Geophys. Res. Lett., 33, L19808, doi:10.1029/2006GL026910, 2006.

Pickett, H. M., Drouin, B. J., Canty, T., et al.: Validation of Aura Microwave Limb Sounder $\mathrm{OH}$ and $\mathrm{HO}_{2}$ measurements, J. Geophys. Res., 113, D16S30, doi:10.1029/2007JD008775, 2008.

Plumb, R. A. and Bell, R. C.: A model of the quasi-biennial oscillation on an equatorial beta-plane, Q. J. Roy. Meteorol. Soc., 108, 335-352, 1982.

Pumphrey, H. C., Jimenez, C. J., and Waters, J. W.: Measurement of HCN in the middle atmosphere by EOS MLS, Geophys. Res. Lett., 33(8), L08804, doi:10.1029/2005GL025656, 2006.

Pumphrey, H. C., Boone, C., Walker, K. A., Bernath, P., and Liversey, N. J.: Tropical tape recorder observed in HCN, Geophys. Res. Lett., 35, L05801, doi:10.1029/2007/GL032137, 2008.

Randel, W. and Wu, F.: Isolation of the ozone QBO in SAGE II data by singular-value decomposition, J. Atmos. Sci., 53, 2546-2559, 1996.

Randel, W. J., Wu, F., Russell III, J. M., Roche, A., and Waters, J. W.: Seasonal Cycle and QBO Variations in Stratospheric $\mathrm{CH}_{4}$ and $\mathrm{H}_{2} \mathrm{O}$ Observed in UARS HALOE Data, J. Atmos. Sci., 55, 163-185, 1998.

Randel, W. J. and Wu, F.: A stratospheric ozone profile data set for 1979-2005: Variability, trends, and comparison with column ozone data, J. Geosphy. Res., 112, D06313, doi:10.1029/2006JD007339, 2007.

Rinsland, C. P., Goldman, A., Murcray, F. J., et al.: Infrared solar spectroscopic measurements of free tropospheric $\mathrm{CO}, \mathrm{C}_{2} \mathrm{H}_{6}$, and $\mathrm{HCN}$ above Mauna Loa, Hawaii: Seasonal variations and evidence for enhanced emissions from the Southeast Asian tropical fires 1997-1998, J. Geophys. Res., 104(D15), 18667-18680, 1999.
Rinsland, C. P., Mahieu, E., Zander, R., Demoulin, P., Forrer, J., and Buchmann, B.: Free tropospheric $\mathrm{CO}, \mathrm{C}_{2} \mathrm{H}_{6}$, and $\mathrm{HCN}$ above central Europe: Recent measurements from the Jungfraujoch station including the detection of elevated columns during 1998, J. Geophys. Res., 105(D19), 24235-24249, 2000.

Rinsland, C. R., Goldman, A., Zander, R., and Mahieu, E.: Enhanced tropospheric HCN columns above Kitt Peak during the 1982-1983 and 1997-1998 El Nino warm phases, J. Quant. Spectrosc. Ra., 69, 3-8, 2001.

Rinsland, C. P., Goldman, A., Hannigan, J. W., Wood, S. W., Chiou, L. S., and Mahieu, E.: Long-term trends of tropospheric carbon monoxide and hydrogen cyanide from analysis of high resolution infrared solar spectra, J. Quant. Spectrosc. Ra., 104, 40-51, 2007.

Schneider, J., Burger, V., and Arnold, F.: Methyl cyanide and hydrogen cyanide measurements in the lower stratosphere: Implications for methyl cyanide sources and sinks, J. Geophys. Res., 102(D21), 25501-25506, 1997.

Schoeberl, M. R., Roche, A. E., Russell III, J. M., Ortland, D., Hays, P. B., and Waters, J. W.: An estimation of the dynamical isolation of the tropical lower stratosphere using trace gas observations of the quasi-biennial oscillation, Geophys. Res. Lett., 24, 53-56, 1997.

Schoeberl, M. R., Duncan, B. N., Douglass, A. R., Waters, J., Liversey, N., Read, W., and Filipiak, M.: The carbon monoxide tape recorder, Geophys. Res. Lett., 33, L12811, doi:10.1029/2006GL026178, 2006.

Schoeberl, M. R., Douglass, A. R., Newman, P. A., et al.: QBO and annual cycle variations in tropical lower stratosphere trace gases from HALOE and Aura MLS observations, J. Geophys. Res., 113, D05301, doi:10.1029/2007JD008678, 2008.

Singh, H. B., Salas, L., Herlth, D., et al.: In situ measurements of $\mathrm{HCN}$ and $\mathrm{CH}_{3} \mathrm{CN}$ over the Pacific Ocean: Sources, sinks and budgets, J. Geophys. Res., 108, 8795, doi:10.1029/2002JD003006, 2003.

Streets, D. G., Bond, T. C., Carmichael, G. R., et al.: An inventory of gaseous and primary aerosol emissions in Asia in the year 2000, J. Geophys. Res., 108(D21), 8809, doi:10.1029/2002JD003093, 2003.

van der Werf, G. R., Randerson, J. T., Giglio, L., Collatz, G. J., Kasibhatla, P. S., and Arellano Jr., A. F.: Interannual variability in global biomass burning emissions from 1997 to 2004, Atmos. Chem. Phys., 6, 3423-3441, 2006, http://www.atmos-chem-phys.net/6/3423/2006/.

Wand, M. P. and Jones, M. C.: Kernel Smoothing, Chapman and Hall, London, UK, 1995.

Waters, J. W.: The Earth Observing System Microwave Limb Sounder (EOS MLS) on the Aura satellite, IEEE T. Geosci. Remote, 44(5), 1106-1121, 2006.

Zhao, Y., Kondo, Y., Murcray, F. J., et al.: Seasonal variations of HCN over northern Japan measured by ground-based infrared solar spectroscopy, J. Geophys. Res., 27, 2085-2088, 2000.

Zhao, Y., Strong, K., Kondo, Y., et al.: Spectroscopic measurements of tropospheric $\mathrm{CO}, \mathrm{C}_{2} \mathrm{H}_{6}, \mathrm{C}_{2} \mathrm{H}_{2}$, and $\mathrm{HCN}$ in northern Japan, J. Geophys. Res., 107(D8), 4343, doi:10.1029/2001JD000748, 2002. 